\title{
Isolation of rat Schwann cells based on cell sorting
}

\author{
MI SHEN ${ }^{1,2 *}$,WEI TANG ${ }^{2 *}$, ZHENG CAO $^{2}$, XUEMIN CAO $^{2}$ and FEI DING ${ }^{2}$ \\ ${ }^{1}$ School of Biology and Basic Medical Science, Suzhou University, Suzhou, Jiangsu 215006; ${ }^{2}$ Jiangsu Key Laboratory of \\ Neuroregeneration, Co-innovation Center of Neuroregeneration, Nantong University, Nantong, Jiangsu 226001, P.R. China
}

Received May 25, 2016; Accepted April 19, 2017

DOI: $10.3892 / \mathrm{mmr} .2017 .6777$

\begin{abstract}
The present study presented a protocol that can be used to obtain rapidly a high purity of proliferating rat Schwann cells from freshly dissociated rat peripheral nerves. The sciatic nerves of newborn rats (1-3 day old) were dissociated, and the Schwann cells (SCs) were purified using fluorescence-activated cell sorting (FACS) based on the SC membrane-specific expression of the low-affinity nerve growth factor receptor, $\mathrm{p} 75^{\mathrm{NGFR}}$ and oligodendrocyte marker 4 . Following sorting, the cells were plated on poly-l-lysine-coated dishes in SC culture medium containing DMEM with $10 \%$ FBS, $1 \%$ penicillin/streptomycin, $2 \mu \mathrm{M}$ forskolin and $10 \mathrm{ng} / \mathrm{ml} \mathrm{HRG}$. The purified rat SCs were propagated for passaging until confluent. This protocol resulted in SC cultures, which were $>98 \%$ pure. This FACS-based protocol can be used to facilitate future investigations of general SC biology.
\end{abstract}

\section{Introduction}

Rats are widely used in experiments based on surgery, as it is easier to perform surgery in rats, including spinal cord injury (1), peripheral nerve system injury (2) and brain injection (3), compared with mice. Certain experiments examining nerve injury in young models require cells from newborn and young rats. It is easier to perform surgery on newborn rats than mice, for example in the establishment of models of brachial plexus injury (4). Schwann cells (SCs) are the principal glial cells of the peripheral nervous system (PNS) and are involved in a wide range of biological and pathological process. Tissue engineering of peripheral nerves and ex vivo gene therapy requires rat SCs of a highly purity (5). Primarily cultured rat SCs are essential for the investigation of molecular mechanisms regulating the proliferation, survival, differentiation

Correspondence to: Professor Fei Ding, Jiangsu Key Laboratory of Neuroregeneration, Co-innovation Center of Neuroregeneration, Nantong University, 19 Qixiu Road, Nantong, Jiangsu 226001, P.R. China

E-mail: dingfei@ntu.edu.cn

${ }^{*}$ Contributed equally

Key words: Schwann cells, fluorescence-activated cell sorting, rat and myelination of SCs $(6,7)$. They are also useful for the development of efficient transplantation for the regeneration of injury to the spinal cord or PNS $(6,7)$. In regenerative medicine approaches, the preparation of a highly-enriched SC population is required in SC transplantation (8). Minimization of the number of contaminating fibroblasts, which can affect the biological analysis and experimentation of SCs, and increase scar tissue formation, is required. For this purpose, the present study modified the techniques of several previously published protocols and developed a method for the isolation and enrichment of rat SCs from sciatic nerves (9-14).

A problem in preparing SCs is fibroblast contamination and the overgrowth of SCs by fibroblasts in long-term culture. Therefore, several methods exist to separately remove either fibroblast cells from the SC cultures or SCs from fibroblasts, as a form of purification (15). The use of antimitotic chemicals is a commonly used technique to inhibit fibroblast growth on the basis of the higher proliferation rate of fibroblasts (9). Furthermore, the preferential surface expression of Thy-1 by fibroblast cells can be exploited by using anti-Thy1 antibodies, in conjunction with complement-mediated cell lysis (16). Other selective purification methods include the use of magnetic beads labeled with low-affinity nerve growth factor receptor ( $\mathrm{p} 75^{\mathrm{NGFR}}$ ) antibodies, with physical removal and subsequent isolation (12-17). Similarly, the use of magnetic beads labeled with Thy-1 antibody to remove fibroblast cells has been reported (18). Nonspecific purification methods are also common and include a 'cold-jet' technique, in which ice-cold culture medium is added to impure cultures followed by a rapid aspiration step $(19,20)$. This method preferentially removes weakly adherent SCs whereas the more adherent fibroblast cells remain on the dishes. A method utilizing immunopanning to deplete macrophages and fibroblasts from the nerve cell suspension, and to positively select for SCs has also been used $(21,22)$.

In order to examine the general biology of SCs, the present study aimed to achieve a method of harvesting SCs rapidly. Cell biology can be affected by a long duration of culture in vitro, chemicals, growth factors and serum. Therefore, the present study aimed to develop a simple protocol to generate highly purified rat SCs by cell sorting using p75 and oligodendrocyte marker $4(\mathrm{O} 4)$, which resulted in $98 \%$ pure SC cultures. According to previous studies, p75 and $\mathrm{O} 4$ are used as markers for the isolation of SC $(11,19,21,22)$. p75 is reported to be expressed in SCs, with the exception of myelinating SCs (23-25), whereas O4 is expressed in SCs, including 
myelinating SCs (23-26). p75 and O4 are surface markers, which enables labeling of living SCs and sorting of the cells. Therefore, the two antibodies can be jointly used to label SCs in vivo to obtain the maximum number of cells. Following sorting, SCs can be cultured in SC culture medium to stimulate cell growth and differentiation, or analyzed immediately. This method is potentially rapid, efficient and reproducible, thus facilitating SC isolation, and promoting SC-associated investigations and applications.

\section{Materials and methods}

Establishment of rat SC cultures for fluorescence-activated cell sorting (FACS) and following FACS. The sterile removal of sciatic nerves was performed on newborn rats (1-3 day old) housed in SPF conditions. The animals were supplied by the Experimental Animal Center of Nantong University (Nantong, China) and were maintained at $24^{\circ} \mathrm{C}$ with a $12-\mathrm{h}$ light/dark cycle and a routine provision of food and water. All animal experiments were performed in accordance with the Industrial Animal Care Guidelines of Nantong University (Nantong, China) and approved by the Administration Committee of Experimental Animals (Jiangsu, China). The nerves were pooled and cut into $1 \mathrm{~nm}$ sections in Hibernate $\mathrm{E}$ (BrainBits, LLC, Springfield, IL, USA) containing 2\% B27 (Sigma-Aldrich; Merck KGaA, Darmstadt, Germany) on ice. The tissues were then harvested by centrifugation for $5 \mathrm{~min}$ at $139 \mathrm{x} \mathrm{g}$ and $4^{\circ} \mathrm{C}$. The supernatant was discarded and $1 \%$ collagenase (Gibco; Thermo Fisher Scientific, Inc., Waltham, MA, USA) was added and incubated at $37^{\circ} \mathrm{C}$ for $20 \mathrm{~min}$, following which $0.125 \%$ trypsin (Gibco; Thermo Fisher Scientific, Inc.) was added and incubated for another $10 \mathrm{~min}$. Digestion was terminated with DMEM (Gibco; Thermo Fisher Scientific, Inc.) and 10\% fetal bovine serum (FBS; Gibco; Thermo Fisher Scientific, Inc.). Dissociation was achieved by mechanical dissociation through a 1-ml Pasteur pipette. The cells were centrifuged for $5 \mathrm{~min}$ at $210 \mathrm{x} \mathrm{g}$, and $4^{\circ} \mathrm{C}$. The cell sediment was rinsed twice using PBS and suspended in $0.1 \mathrm{M}$ PBS for antibody labeling. Following FACS, the sorted cells were seeded onto dishes or slides in DMEM with $10 \%$ FBS and $1 \%$ penicillin/streptomycin in a $37^{\circ} \mathrm{C}, 5 \% \mathrm{CO}_{2}$ incubator and cultured for $4 \mathrm{~h}$. Then, the culture medium was replaced with SC culture medium consisting of DMEM with $10 \%$ FBS, $1 \%$ penicillin/streptomycin, $2 \mu \mathrm{M}$ forskolin and $10 \mathrm{ng} / \mathrm{ml}$ HRG (both from Sigma; Merck KGaA) and the cell culture was maintained subsequently in a $37^{\circ} \mathrm{C}, 5 \% \mathrm{CO}_{2}$ incubator for 24-48 h.

Coating cell culture surfaces. At $24 \mathrm{~h}$ prior to seeding of the SCs, plastic or glass surfaces were coated with poly-L-lysine (Sigma; Merck KGaA) and incubated for $30 \mathrm{~min}$ at room temperature. The dishes and slides were rinsed three times with sterile water, dried naturally and then stored at room temperature until use.

Labeling of SCs with $p 75$ and $O 4$ for FACS. The cells isolated from the sciatic nerves were prepared for use for FACS. The cells were counted and divided into four groups: Negative control; positive control for p75 and $\mathrm{O} 4$, and the antibodies labeled separately. The cells for labeling were incubated with
Table I. Primer sequences for reverse transcription-quantitative polymerase chain reaction analysis.

\begin{tabular}{|c|c|}
\hline Gene & Primer sequence $\left(5^{\prime}-3^{\prime}\right)$ \\
\hline $18 \mathrm{~S}$ & $\begin{array}{l}\text { agtccetgccetttgtacaca } \\
\text { cgttccgagggectcact }\end{array}$ \\
\hline Sox 10 & $\begin{array}{l}\text { cccaggtgaagacagaga } \\
\text { agactgagggaggtgtagg }\end{array}$ \\
\hline P0 & $\begin{array}{l}\text { ggacatagtgggcaagac } \\
\text { aggtagaagagcaacagca }\end{array}$ \\
\hline Sox 2 & $\begin{array}{l}\text { cagctcgcagacctacat } \\
\text { tcggacttgaccacagag }\end{array}$ \\
\hline Krox-20 & $\begin{array}{l}\text { accacctcaccactcaca } \\
\text { actgetcttcetctcettct }\end{array}$ \\
\hline Pmp22 & $\begin{array}{l}\text { tggctttgcttacatcct } \\
\text { ttggttttctggtttcctt }\end{array}$ \\
\hline Necl-4 & $\begin{array}{l}\text { atggtgtggtgctctgtc } \\
\text { ttcttctttccgcttgtg }\end{array}$ \\
\hline Tubb3 & $\begin{array}{l}\text { gtcaaggtagcggtgtgt } \\
\text { gtgaactccatctcatcca }\end{array}$ \\
\hline
\end{tabular}

Sox10, SRY-Box 10; P0, myelin protein 0; Sox2, SRY-Box 2; Krox-20, early growth response 2; Pmp22, peripheral myelin protein 22; Necl-4, nectin-like molecule 4; Tubb3, tubulin $3 \beta$ chain.

FITC-conjugated anti-p75 (ab62122; Abcam, Cambridge, MA, USA) diluted 1:100 and PE-conjugated anti-O4 antibodies (FAB1326P; R\&D Systems, Inc., Minneapolis, MN, USA) diluted 1:10 in PBS for $30 \mathrm{~min}$ at room temperature. The cells were then washed twice with PBS to remove the unbounded antibodies. Finally, the labeled cells were resuspended in $500 \mu 1$ PBS ready for FACS.

FACS of p75-and O4-labeled SCs. FACS was performed on a FACSAria cell sorter using FACSDiva software (BD Biosciences, San Jose, CA, USA). Prior to sorting, the sample was filtered to remove any columns and aggregates. FITC and PE fluorescence were excited at a wavelength of $488 \mathrm{~nm}$ and collected through a 520 and 578 bandpass interference filter. Compensation for FITC and PE were adjusted. The cells positive for p75 and $\mathrm{O} 4$ were collected. Following cell sorting, the collected cells were reassessed using FACS in order to determine the sorting purity. The sorted cells were then plated on the dishes and slides. After 4-6 h, The cells were rechecked and their medium was replaced with the SC culture medium.

Immunocytochemistry. The cells plated onto coated glass coverslips were cultured for $24 \mathrm{~h}$ or until $80 \%$ confluent, and fixed for $30 \mathrm{~min}$ in $4 \%$ paraformaldehyde ( $\mathrm{pH} \mathrm{7.2)} \mathrm{at} \mathrm{room}$ temperature. The cells were then washed once in PBS, blocked for $2 \mathrm{~h}$ in blocking buffer [0.3\% Triton X-100 and 10\% goat serum (ZLI-9021; Zhongshan Jinqiao Biotechnology Co., Ltd., Beijing, China) in $0.01 \mathrm{M} \mathrm{PBS}$ ] for $60 \mathrm{~min}$ at $37^{\circ} \mathrm{C}$, and incubated with anti-S100 $\beta$ antibody, anti-glial fibrillary acidic protein (GFAP) antibody and anti-tubulin $3 \beta$ chain (Tubb3) antibody (ab212816, ab7260 and ab18207; 1:200; Abcam), 
A

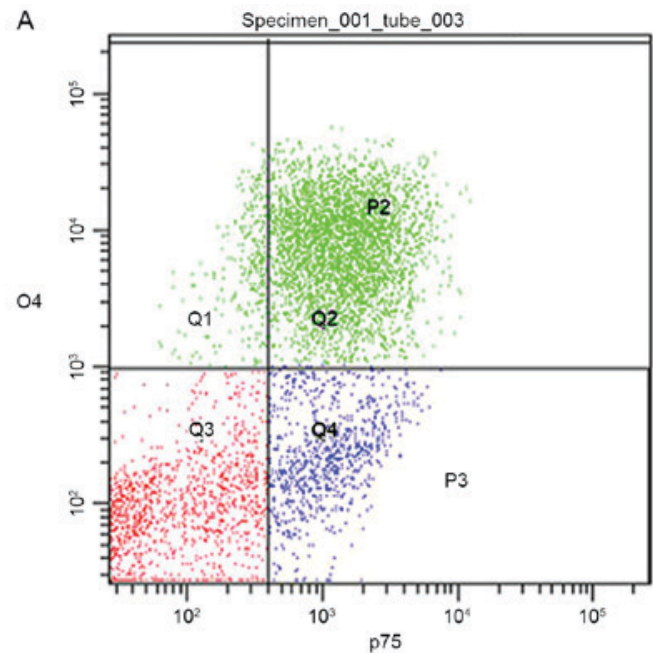

\begin{tabular}{|c|c|c|c|}
\hline \multicolumn{4}{|c|}{ Tube: tube_003 } \\
\hline Population & \#Events & \%Parent & \%Total \\
\hline All events & 10,000 & \#\#\# & 100.0 \\
\hline & 7,182 & 71.8 & 71.8 \\
\hline QQ1 & 251 & 3.5 & 2.5 \\
\hline 凶Q2 & 3,515 & 48.9 & 35.2 \\
\hline QQ3 & 2,588 & 36.0 & 25.9 \\
\hline Q Q4 & 828 & 11.5 & 8.3 \\
\hline$P_{2}$ & 3,765 & 52.4 & 37.6 \\
\hline$P_{3}$ & 825 & 11.5 & 8.2 \\
\hline
\end{tabular}

C

$\mathrm{D}$

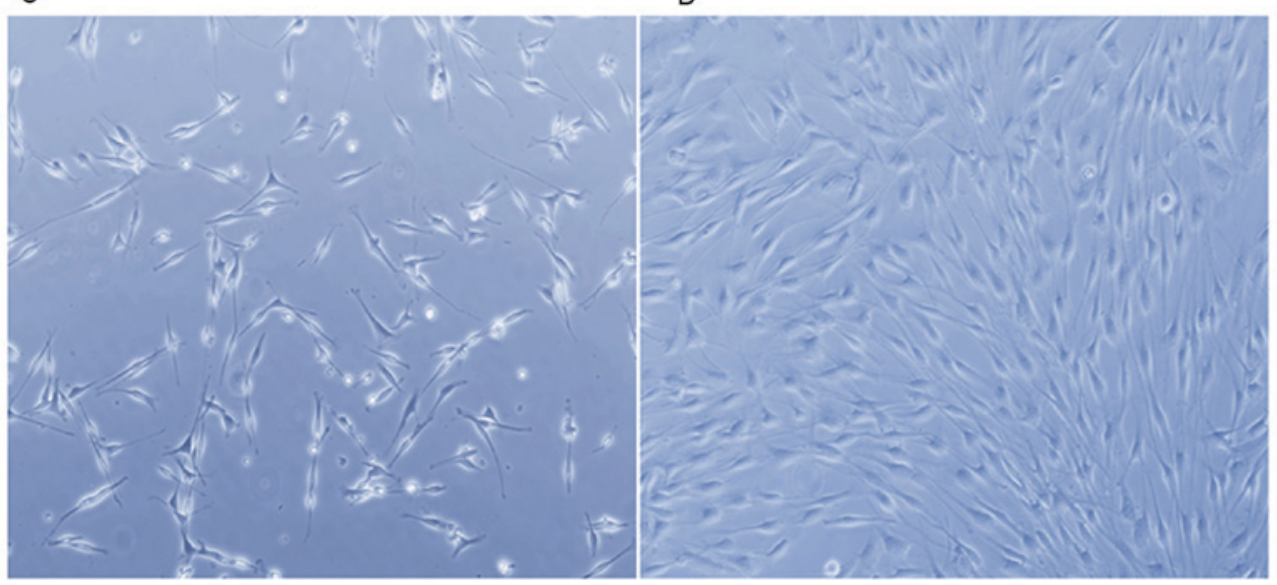

Figure 1. FACS of isolated cells from rat sciatic nerves. (A) FACS of labeled cells. Cells in the P2 (green) and P3 (purple) gate were sorted, and (B) 64\% of the cells were labeled with both p75 and O4. Q1 region represents O4-labeled positive, Q2 represents both O4- and p75-labeled positive, Q3 represents both O4- and p75-labeled negative and Q4 represents p75-labeled positive. (C) Sorted cells cultured for $4 \mathrm{~h}$ exhibited typical cell morphology of SCs under phase-contrast microscopy, including cell debris (magnification, x20). (D) Sorted cells cultured for $72 \mathrm{~h}$ in SC growth culture media (magnification, x20). FACS, fluorescence-activated cell sorting; SCs, Schwann cells; O4, oligodendrocyte marker 4.

respectively at $4^{\circ} \mathrm{C}$ overnight, followed by incubation with FITC-conjugated rabbit anti mouse $\mathrm{IgG}$ or $\mathrm{Cy} 3$-conjugated goat anti rabbit IgG (ab6724 and ab6939; 1:500; Abcam) for $2 \mathrm{~h}$ at room temperature, respectively. The cells were also stained with $5 \mu \mathrm{g} / \mathrm{ml}$ Hoechst 33342 dye at $37^{\circ} \mathrm{C}$ for $20 \mathrm{~min}$. The fluorescence was visualized under a TCS SP5 confocal microscope (Leica Microsystems GmbH, Wetzlar, Germany).

RNA extraction and reverse transcription-quantitative polymerase chain reaction (RT-qPCR). Total RNA was extracted from the sorted SCs cultured for $72 \mathrm{~h}$ using TRIzol (Invitrogen; Thermo Fisher Scientific, Inc.) and cDNA was synthesized from the total RNA using the SuperScript First-Strand Synthesis system (Invitrogen; Thermo Fisher Scientific, Inc.). The qPCR analysis was performed using FastStart ${ }^{\circledR}$ SYBR-Green qPCR Master Mix (Roche Diagnostics GmbH, Mannheim, Germany) according to the manufacturer's protocol. A $50 \mu \mathrm{l}$ reaction volume consisted of $1 \mu \mathrm{l} \mathrm{cDNA}, 25 \mu \mathrm{l} 2 \mathrm{X}$ Fast SYBR-Green Master Mix, $1 \mu 1$ of each primer and $22 \mu 1$ of RNase/DNase-free water. A three-step fast cycle protocol was used, with cycling conditions as follows: Denaturation at $95^{\circ} \mathrm{C}, 10 \mathrm{sec}$; annealing at $60^{\circ} \mathrm{C}, 30 \mathrm{sec}$; and, extension at $70^{\circ} \mathrm{C}$,
$10 \mathrm{sec}$ (Applied Biosystems; Thermo Fisher Scientific, Inc.). The data were analyzed using the software supplied by the manufacturer (Applied Biosystems; Thermo Fisher Scientific, Inc.). The primer sequences are listed in Table I.

\section{Results and Discussion}

The cell mixture labeled with p75 and $\mathrm{O} 4$ antibodies was analyzed using FACSAria I (Fig. 1A). The p75- and O4-positive populations were sorted, the percentages of which are demonstrated in Fig. 1B. Following sorting, the cells were plated on poly-L-lysine coated glass cover slips or dishes. After $24 \mathrm{~h}$, almost all of the cells exhibited the classical morphology of SCs (Fig. 1C). The sorted cells were then cultured for $72 \mathrm{~h}$ in SC growth medium. The cells proliferated to confluence (Fig. 1D). Immunocytochemistry with anti-S100 $\beta$ and anti-GFAP antibodies, and S100 $\beta$ and GFAP proteins serving as SC markers, provided further evidence of the cell purity of the FACS cells at $24 \mathrm{~h}$ (Fig. 2A). The purity of the SCs cultured for $72 \mathrm{~h}$ was confirmed using flow cytometry (Fig. 2B), which indicated that $>98 \%$ of the cell population was $\mathrm{S} 100 \beta$-positive. These data indicated that cell 
A

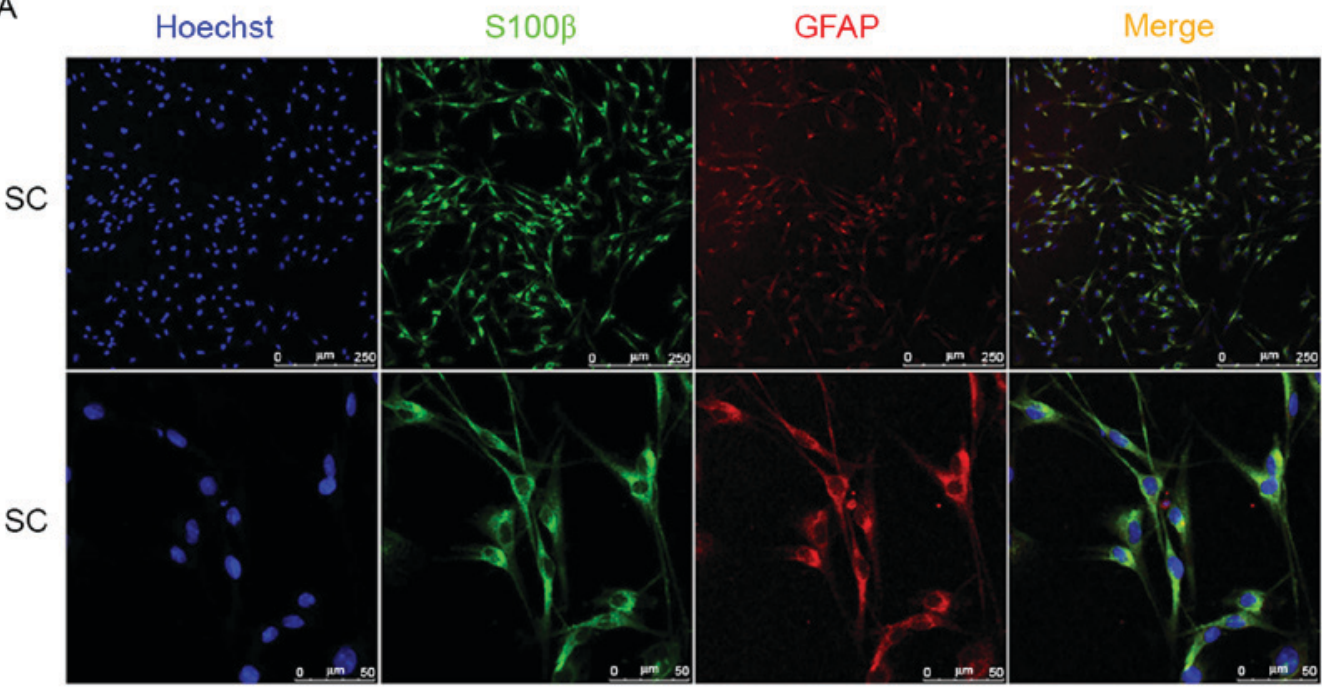

B

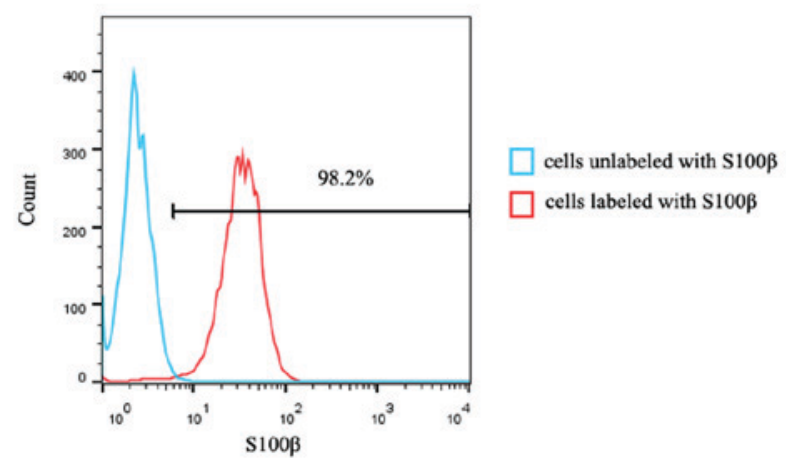

Figure 2. Characterization of sorted SCs. (A) Immunocytochemistry combined with S100ß (green color), GFAP (red color) and Hoechst 33342 staining (blue color) of sorted SCs cultured for $24 \mathrm{~h}$ (magnifications, x20 and x63). (B) Flow cytometric analysis data showing that $98.2 \%$ of the cell population was S100 $\beta$-positive. The blue line represents the cells labeled with S100 $\beta$ antibodies and the red line represents the unlabeled (blank) cells. SCs, Schwann cells; GFAP, glial fibrillary acidic protein.

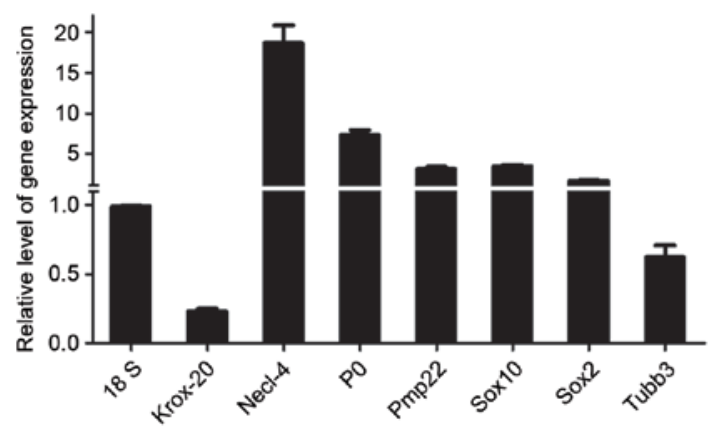

Figure 3. Validation of SC-associated genes using RT-qPCR. Histogram showing the mRNA expression levels of Krox-20, Necl-4, P0, Pmp22, Sox 10, Sox 2 and Tubb3 relative to that of 18s, in sorted SCs cultured for $72 \mathrm{~h}$. Results were determined using RT-qPCR. SCs, Schwann cells; RT-qPCR, reverse transcription-quantitative polymerase chain reaction. Sox10, SRY-Box 10; P0, myelin protein 0; Sox2, SRY-Box 2; Krox-20, early growth response 2; Pmp22, peripheral myelin protein 22; Necl-4, nectin-like molecule 4; Tubb3, tubulin $\beta 3$ class III.

purity was markedly enhanced following sorting, with almost 99\% purity achieved. Using RT-qPCR analysis, the mRNA expression levels of genes expressed in SCs were determined, as demonstrated in Fig. 3. SCs isolated by sorting can express myelinating and non-myelinating SC markers (26). Of note,
Tubb3, which is expressed in neurons, was present in the SCs isolated by sorting and validated using RT-qPCR analysis and immunocytochemistry (Figs. 3 and 4). Our previous study reported that Tubb3 was expressed in primary cultured SCs (9). To a degree, the results of the present study provide further evidence in support of the previous study.

The aim of the present study was to obtain highly enriched pure SCs from rat peripheral nerves. Several studies have attempted to improve the purification of SCs in an efficient and convenient method, one which is less time consuming and reduces cell loss $(10-18,20-22)$. These methods can be divided into several approaches: i) Differential adhesion and differential digestion, or a cold jet technique, based on the different adherence abilities of SC and fibroblasts; ii) removal of fibroblasts from the SC cell culture by complement-mediated cell killing; iii) cell sorting based on specific cell surface biomarkers of SCs. The method used in the present study, which employed FACS, may be more convenient and take less time. In the process of cell sorting, cells can be plated directly in dishes, wells or tubes according to the requirements of the subsequent experiment. The cells can be analyzed directly and rapidly from the in vivo environment. The cells can also be cultured in SC culture medium containing forskolin and HRG to improve cell proliferation and differentiation for future use. The purified SCs can be used immediately for cell 


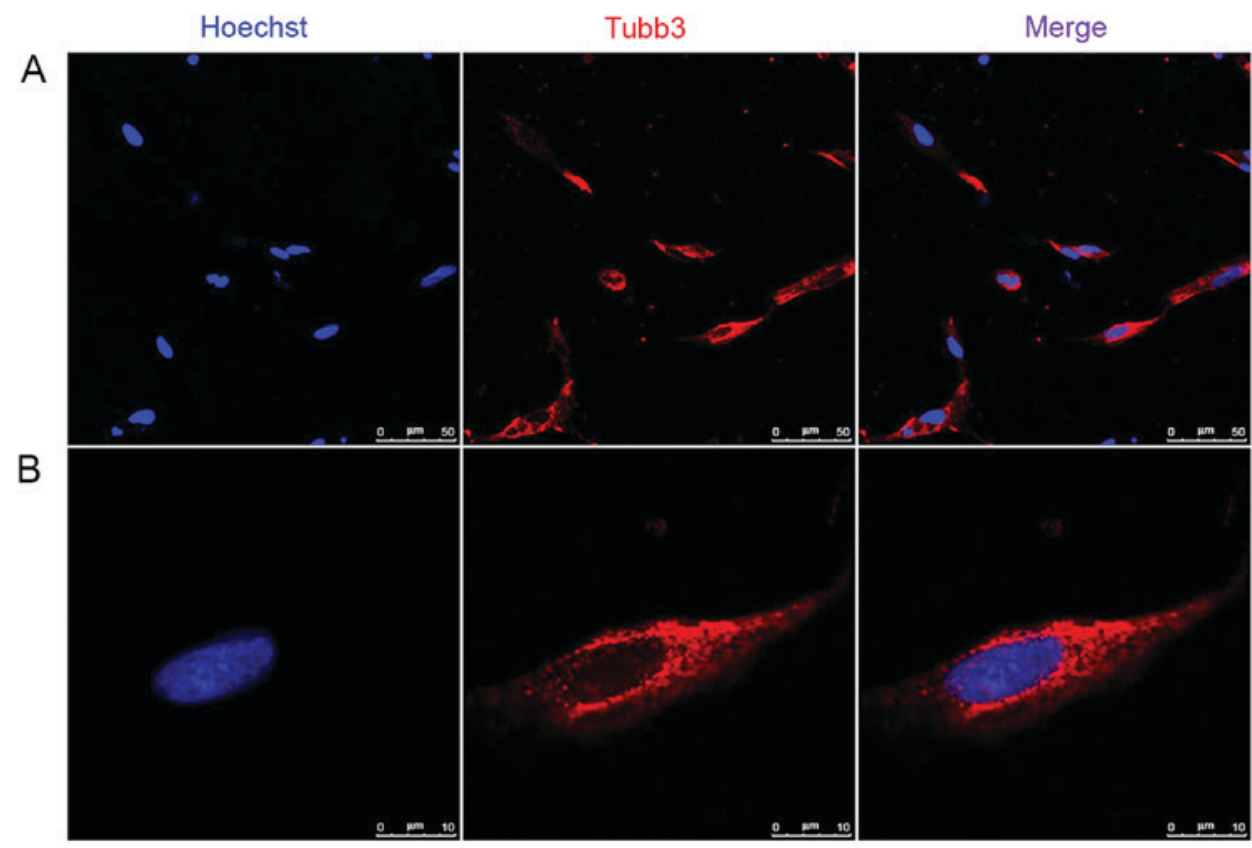

Figure 4. Validation by immunocytochemistry. (A) Light micrographs, captured using a TCS SP5 confocal microscope equipped with a $63 \mathrm{X}$ oil immersion lens showing sorted Schwann cells cultured for $24 \mathrm{~h}$ combined with Tubb3 (red color) and Hoechst 33342 staining (blue color). (B) Images at a higher magnification of one cell each per antigen. Tubb3, tubulin $3 \beta$ chain.

transplantation or passaged and frozen for future use. It may also have less of an effect on alterations of SC biology, as fewer chemicals are used in the process. The method presented in the present study enabled the isolation of SCs from rat peripheral nerves within $24 \mathrm{~h}$, and can potentially be applied to SCs from other species and other sources depending on the appropriate antibodies.

FACS has the significant advantage in that cells with specific marker combinations can be isolated in one step, provided that each marker is labeled with a different fluoresce. The protocol presented in the present study is well-suited to isolating SCs for use in general SC biological analysis and tissue engineering. In previous studies, either p75 or O4 has been selected as a surface marker for SC purification. In the present study, both of these antibodies were used to label SCs in the rat primary cell mixture derived from sciatic nerve tissues. This enabled harvesting of the highest number of SCs possible, as cells positive to $\mathrm{p} 75$ alone, to $\mathrm{O} 4$ alone and to p75 and O4 combined (as demonstrated in the Q1, Q2 and Q3 regions of Fig. 1A) were all identified as SCs for harvest. Therefore, this FACS-based method offered another method for isolating SCs in vivo.

In conclusion, the novel method used in the present study for obtaining primary cultured SCs from the sciatic nerves of rats offers potential for facilitating investigations and applications of SC biology.

\section{Acknowledgements}

This study was supported by a project funded by the National Natural Science Foundation of China (grant nos. 81371389 , 31300942 and 31500927) and the Priority Academic Program Development of Jiangsu Higher Education Institutions.

\section{References}

1. Aras M, Altas M, Motor S, Dokuyucu R, Yilmaz A, Ozgiray E, Seraslan Y and Yilmaz N: Protective effects of minocycline on experimental spinal cord injury in rats. Injury 46: 1471-1474, 2015.

2. Zhou S, Zhang S, Wang Y, Yi S, Zhao L, Tang X, Yu B, Gu X and Ding F: miR-21 and miR-222 inhibit apoptosis of adult dorsal root ganglion neurons by repressing TIMP3 following sciatic nerve injury. Neurosci Lett 586: 43-49, 2015.

3. Peelaerts W, BoussetL, Van der Perren A,Moskalyuk A,PulizziR, Giugliano M, Van den Haute C, Melki R and Baekelandt V: $\alpha$-Synuclein strains cause distinct synucleinopathies after local and systemic administration. Nature 522: 340-344, 2015.

4. Wu JX, Chen L, Ding F and Gu YD: A rat model study of atrophy of denervated musculature of the hand being faster than that of denervated muscles of the arm. J Muscle Res Cell Motil 34: 15-22, 2013.

5. Wang Y, Zhao Y, Sun C, Hu W, Zhao J, Li G, Zhang L, Liu M, Liu Y, Ding F, et al: Chitosan degradation products promote nerve regeneration by stimulating schwann cell proliferation via miR-27a/FOXO1 Axis. Mol Neurobiol 53: 28-39, 2016.

6. di Summa PG, Kalbermatten DF, Pralong E, Raffoul W, Kingham PJ and Terenghi G: Long-term in vivo regeneration of peripheral nerves through bioengineered nerve grafts. Neuroscience 181: 278-291, 2011.

7. Moradi F, Bahktiari M, Joghataei MT, Nobakht M, Soleimani M, Hasanzadeh G, Fallah A, Zarbakhsh S, Hejazian LB, Shirmohammadi M and Maleki F: BD PuraMatrix peptide hydrogel as a culture system for human fetal Schwann cells in spinal cord regeneration. J Neurosci Res 90: 2335-2348, 2012.

8. Kanno H, Pearse DD, Ozawa H, Itoi E and Bunge MB: Schwann cell transplantation for spinal cord injury repair: Its significant therapeutic potential and prospectus. Rev Neurosci 26: 121-128, 2015 .

9. Shen M, Ji Y, Zhang S, Shi H, Chen G, Gu X and Ding F: A proteome map of primary cultured rat Schwann cells. Proteome Sci 10: 20, 2012

10. Weinstein DE and Wu R: Isolation and purification of primary Schwann cells. Curr Protoc Neurosci: Chapter 3:Unit 3.17, 2001

11. Manent J, Oguievetskaia K, Bayer J, Ratner N and Giovannini M: Magnetic cell sorting for enriching Schwann cells from adult mouse peripheral nerves. J Neurosci Methods 123: 167-173, 2003. 
12. Haastert K, Mauritz C, Chaturvedi S and Grothe C: Human and rat adult Schwann cell cultures: Fast and efficient enrichment and highly effective non-viral transfection protocol. Nat Protoc 2: 99-104, 2007.

13. Mauritz C, Grothe $\mathrm{C}$ and Haastert K: Comparative study of cell culture and purification methods to obtain highly enriched cultures of proliferating adult rat Schwann cells. J Neurosci Res 77: 453-461, 2004.

14. Spiegel I and Peles E: A novel method for isolating Schwann cells using the extracellular domain of Necl1. J Neurosci Res 87: 3288-3296, 2009.

15. Kaewkhaw R, Scutt AM and Haycock JW: Integrated culture and purification of rat Schwann cells from freshly isolated adult tissue. Nat Protoc 7: 1996-2004, 2012.

16. Morrissey TK, Kleitman N and Bunge RP: Isolation and functional characterization of Schwann cells derived from adult peripheral nerve. J Neurosci 11: 2433-2442, 1991.

17. Vroemen M and Weidner N: Purification of Schwann cells by selection of p75 low affinity nerve growth factor receptor expressing cells from adult peripheral nerve. J Neurosci Methods 124: 135-143, 2003

18. Haastert K, Seef P, Stein VM, Tipold A and Grothe C: A new cell culture protocol for enrichment and genetic modification of adult canine Schwann cells suitable for peripheral nerve tissue engineering. Res Vet Sci 87: 140-142, 2009.

19. Teare KA, Pearson RG, Shakesheff KM and Haycock JW: Alpha-MSH inhibits inflammatory signalling in Schwann cells. Neuroreport 15: 493-498, 2004.
20. Jirsová K, Sodaar P, Mandys V and Bär PR: Cold jet: A method to obtain pure Schwann cell cultures without the need for cytotoxic, apoptosis-inducing drug treatment. J Neurosci Methods 78: 133-137, 1997.

21. Lutz AB: Purification of Schwann cells. Cold Spring Harb Protoc 2014: 1234-1236, 2014.

22. Lutz AB: Purification of Schwann cells from the neonatal and injured adult mouse peripheral nerve. Cold Spring Harb Protoc 2014: 1312-1319, 2014.

23. Gordon T: Neurotrophic factor expression in denervated motor and sensory Schwann cells: Relevance to specificity of peripheral nerve regeneration. Exp Neurol 254: 99-108, 2014.

24. Mirsky R, Woodhoo A, Parkinson DB, Arthur-Farraj P, Bhaskaran A and Jessen KR: Novel signals controlling embryonic Schwann cell development, myelination and dedifferentiation. J Peripher Nerv Syst 13: 122-135, 2008.

25. Jessen KR and Mirsky R: The origin and development of glial cells in peripheral nerves. Nat Rev Neurosci 6: 671-682, 2005.

26. Dworski S: Comparison of Schwann cells derived from peripheral nerve with Schwann cells differentiated from skin-derived precursors. Master, 2011. 